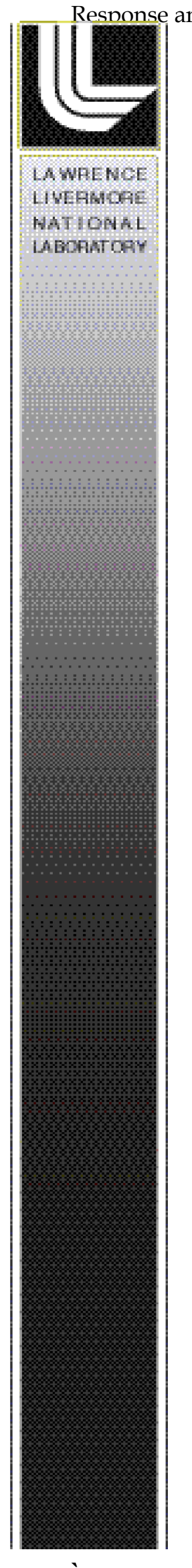

\title{
Draft Guidance: \\ Response, Remediation, and Recovery Checklist for Chemically Contaminated Facilities
}

\author{
E. Raber, S. Mancieri, T. Carlsen, C. Fish, \\ J. Hirabayashi-Dethier, A. Intrepido, D. MacQueen, \\ R. Michalik, and J. Richards
}

August 20, 2007 


\section{Disclaimer}

This document was prepared as an account of work sponsored by an agency of the United States Government. Neither the United States Government nor the University of California nor any of their employees, makes any warranty, express or implied, or assumes any legal liability or responsibility for the accuracy, completeness, or usefulness of any information, apparatus, product, or process disclosed, or represents that its use would not infringe privately owned rights. Reference herein to any specific commercial product, process, or service by trade name, trademark, manufacturer, or otherwise, does not necessarily constitute or imply its endorsement, recommendation, or favoring by the United States Government or the University of California. The views and opinions of authors expressed herein do not necessarily state or reflect those of the United States Government or the University of California, and shall not be used for advertising or product endorsement purposes.

This report has been reproduced directly from the best available copy.

This work was performed under the auspices of the U.S. Department of Energy by University of California, Lawrence Livermore National Laboratory under Contract W-7405-Eng-48. 


\section{Draft Guidance: \\ Response, Remediation, and Recovery Checklist for Chemically Contaminated Facilities}

E. Raber, S. Mancieri, T. Carlsen, C. Fish, J. Hirabayashi-Dethier, A. Intrepido, D. MacQueen, R. Michalik, and J. Richards

\section{August 2007}




\section{Table of Contents}

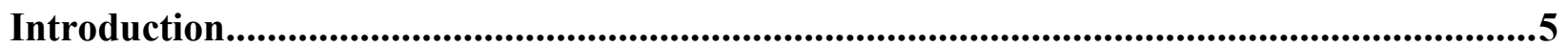

Checklist for Facility Response, Remediation, and Recovery .........................................8

Recommendations for Facility Preparedness ...............................................................12

Appendix A. Incident Command System .............................................................................14

\section{List of Figures}

Figure 1. Response and restoration phases to a chemical event...........................................6

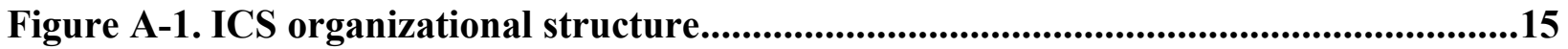

Figure A-2. Members and areas of required expertise of the UC and TWG......................16 


\section{Draft Guidance: Response, Remediation, and Recovery Checklist for Chemically Contaminated Facilities}

\section{Introduction}

A key part of preparedness in the event of a chemical warfare agent (CWA) or toxic industrial chemical (TIC) release at a large facility, such as an airport or subway, is to develop a concept of operations that allows for an effective incident response and recovery. This document is intended as a component of the concept of operations and will be used in the Emergency Operations Center (EOC) as a decision tool for the Unified Command (UC). The Checklist for Facility Response, Remediation, and Recovery presented in this document is principally focused on the Consequence Management Phase (see Figure 1; LLNL 2007a and 2007b) of a chemical release. Information in this document conforms to the National Response Plan (NRP) (DHS 2004) and the National Incident Management System (NIMS 2004). Under these two guidance documents, personnel responsible for managing chemical response and recovery efforts - that is, the decision-makers - are members of an Incident Command (IC), which is likely to transition to a UC in the event of a CWA or TIC attack. A UC is created when more than one agency has incident jurisdiction or when incidents cross political jurisdictions. The location for primary, tactical-level command and management is referred to as the Incident Command Post (ICP), as described in the NRP. Thus, regardless of whether an IC or a UC is used, the responsible entities are located at an ICP. Agencies work together through designated members of the UC to establish their designated Incident Commanders at a single ICP and to establish a common set of objectives and strategies and a single Incident Action Plan.

Initially during the Crisis Management Phase (see Figure 1), the Incident Commander is likely to be the Chief of the fire department that serves the affected facility. As life-safety issues are resolved and the Crisis Management Phase shifts to the Consequence Management Phase, the work of characterization, decontamination, and facility clearance begins. There will likely be a coincident transition in organizational structure as well, and new remediation-focused groups, units, and personnel will be added as remediation needs are anticipated. In most cases, a UC would be formed, if not formed already, to direct the cleanup process jointly and to take ultimate responsibility for all cleanup decisions. The UC would likely include the Transportation Facility Manager or Emergency Operations Manager; representatives from state and local public health, environmental, and emergency management agencies; and Federal agencies, such as the U.S. Environmental Protection Agency. 


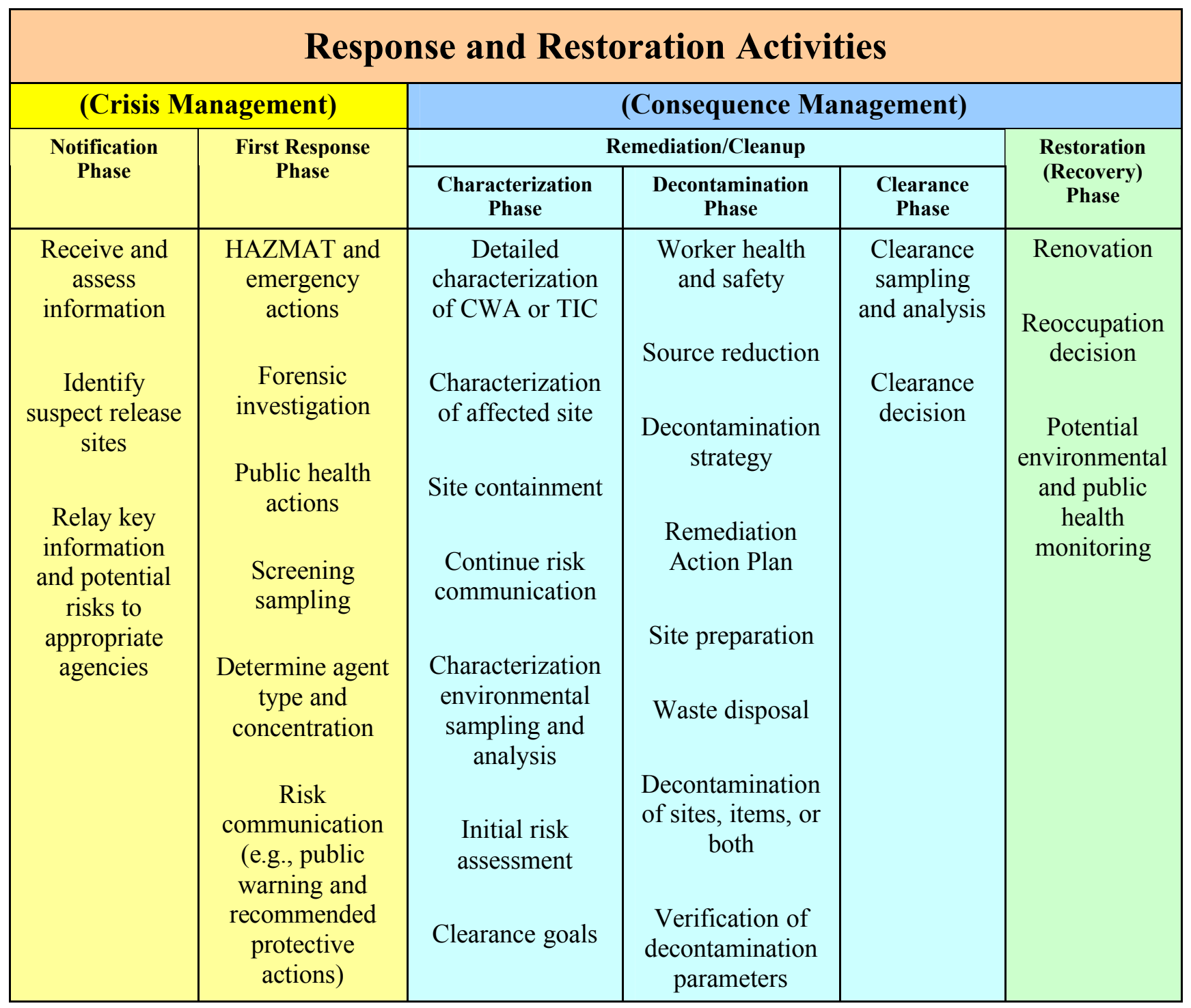

Figure 1. Response and restoration phases to a chemical event. The content of this illustration was developed with interagency cooperation. The focus of this document is on characterization, decontamination, and clearance (areas shaded in blue). Historically, the term Crisis Management referred to the Notification and First-Response Phases; the term Consequence Management referred to the remainder of the phases shown in this illustration.

In an incident involving large-scale chemical contamination, the Governor of the state would typically request, and the President of the United States would likely declare, an emergency under the Stafford Act (1974; amended 2002). In the case of a terrorist-related incident, the Secretary of Homeland Security could determine that the event is an Incident of National Significance on the basis of criteria established in Homeland Security Presidential Directive 5 (HSPD-5), "Management of Domestic Incidents." Incidents of National Significance are those high-impact events that require a coordinated and effective response by an appropriate combination of Federal, state, local, tribal, private-sector, and nongovernmental entities to save 
lives, minimize damage, and provide the basis for long-term community recovery and mitigation activities. If an Incident of National Significance is declared, a Principal Federal Official will be appointed by the Department of Homeland Security (DHS) to facilitate Federal support to the UC structure.

The following Checklist for Facility Response, Remediation, and Recovery presents the critical steps that would be taken by organizations involved in responding to a chemical incident. It is intended for use by key decision-makers in the event that an incident occurs and steps must be taken immediately and systematically. The organizations would follow the Incident Command System (ICS). See Appendix A for more information on the ICS and how the responsible personnel identified in the checklist map into the consequence management organizational structure.

The Notification and First-Response Phases are cursorily addressed in the checklist, whereas the main focus is on consequence management actions. The order of actions is generally sequential. However, depending on the specifics of an event and how a response is implemented, actions may be reordered. For example, preparing a Remediation Action Plan (RAP) is identified in the checklist as a critical step of the Remediation Phase. However, it is likely that preparation of the RAP would begin before completing all actions identified in the Characterization Phase. In addition to the actions recommended in the checklist, any emergency response should comply with notification and response procedures established by the facility, as well as applicable procedures established by the jurisdictional responding agencies. 


\section{Checklist for Facility Response, Remediation, and Recovery}

\begin{tabular}{|c|c|c|}
\hline Responsible Personnel & & Action \\
\hline \multicolumn{3}{|l|}{ Notification Phase } \\
\hline \multirow[t]{3}{*}{$\begin{array}{l}\text { Facility emergency management } \\
\text { organization and law enforcement } \\
\text { or other response organizations }\end{array}$} & $\square$ & $\begin{array}{l}\text { Facility receives notification that: } \\
\text { - A CWA incident has been detected, or } \\
\text { - A CWA incident is suspected, or } \\
\text { - Information about a developing threat is received from an agency or responsible person. }\end{array}$ \\
\hline & $\square$ & $\begin{array}{l}\text { Gather information and continue to assess incident credibility, incident status, potential effect } \\
\text { on the facility, and the degree to which a response is needed. }\end{array}$ \\
\hline & $\square$ & $\begin{array}{l}\text { Facility makes notification, as appropriate, by: } \\
\text { - Following established facility notification protocol, tailored to each stage of a developing } \\
\text { incident, and either alerting responders and agencies (Federal, state, and local) or acting on } \\
\text { direction from them. } \\
\text { - Disseminating available information and initiating protective actions. }\end{array}$ \\
\hline \multicolumn{3}{|l|}{ First-Response Phase } \\
\hline \multirow[t]{9}{*}{$\begin{array}{l}\text { Incident Commander or Facility } \\
\text { Manager }\end{array}$} & $\square$ & $\begin{array}{l}\text { Activate, or coordinate with law enforcement and emergency operations personnel as needed, } \\
\text { to include: } \\
\text { - Security personnel. } \\
\text { - FBI and/or local law enforcement (they will likely control the crime scene to protect } \\
\text { evidence and commence forensic investigation). } \\
\text { - Fire department personnel. } \\
\text { - Public health and medical personnel. } \\
\text { - Hazardous materials (HAZMAT) and/or other screening sampling teams, e.g., Civil } \\
\text { Support Team (CST). }\end{array}$ \\
\hline & $\square$ & $\begin{array}{l}\text { Evacuate, rescue, and/or isolate affected persons, as needed based on the facility's emergency } \\
\text { response plan. }\end{array}$ \\
\hline & $\square$ & Mitigate any conditions posing immediate threat to human health. \\
\hline & $\square$ & $\begin{array}{l}\text { Activate EOC, as appropriate } \\
\text { - Continue to inform responders and agencies (Federal, state, and local) about developing } \\
\text { details related to the incident. }\end{array}$ \\
\hline & $\square$ & Determine if facility operations should be sustained, diverted, or suspended. \\
\hline & $\square$ & Initiate risk communication. \\
\hline & $\square$ & Control access to the affected area. \\
\hline & $\square$ & Implement emergency containment procedures. \\
\hline & $\square$ & $\begin{array}{l}\text { Transition to a Unified Command (UC), if appropriate, as additional agencies and } \\
\text { organizations respond. }\end{array}$ \\
\hline \multirow[t]{3}{*}{ IC or Unified Command } & $\square$ & Confirm identity of specific chemical. \\
\hline & $\square$ & Determine if there is a significant risk to public health. \\
\hline & $\square$ & $\begin{array}{l}\text { Gather new information if necessary, e.g., additional agent analytical testing, medical } \\
\text { symptoms, additional environmental sample analyses, and available intelligence information. }\end{array}$ \\
\hline
\end{tabular}




\section{Checklist continued.}

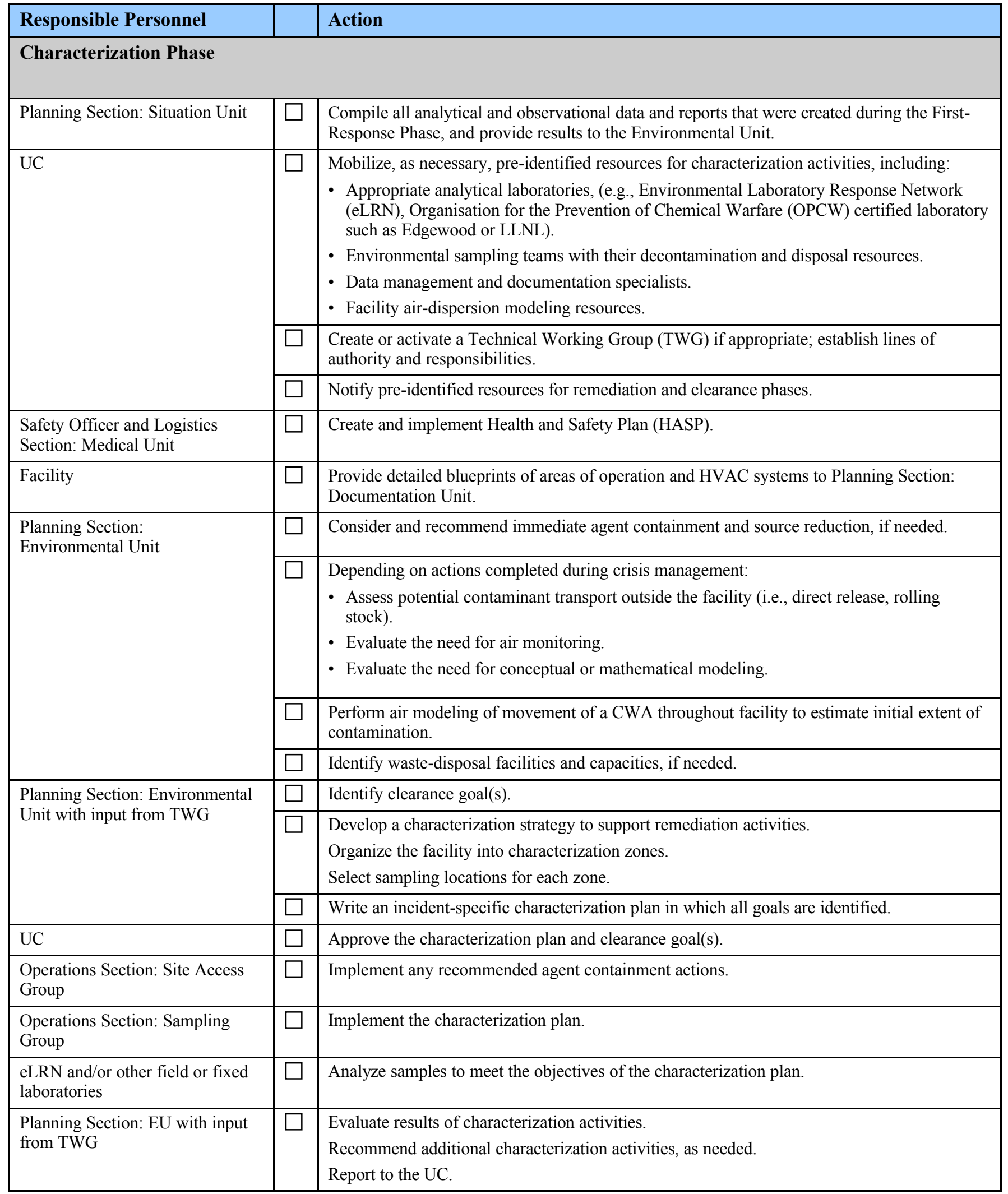




\section{Checklist continued.}

\begin{tabular}{|c|c|c|}
\hline Responsible Personnel & & Action \\
\hline \multicolumn{3}{|l|}{ Decontamination Phase } \\
\hline $\begin{array}{l}\text { Planning Section: Environmental } \\
\text { Unit with input from TWG }\end{array}$ & $\square$ & $\begin{array}{l}\text { Develop measurable decontamination process criteria, as appropriate, based on } \\
\text { characterization results. }\end{array}$ \\
\hline \multirow[t]{4}{*}{$\begin{array}{l}\text { Planning Section: Environmental } \\
\text { Unit with input from TWG }\end{array}$} & $\square$ & $\begin{array}{l}\text { Develop the decontamination strategy, including assessment of potential environmental } \\
\text { impacts of remediation. }\end{array}$ \\
\hline & $\square$ & $\begin{array}{l}\text { Prepare the Remediation Action Plan (RAP), including: } \\
\text { - Areas to decontaminate and types of surfaces involved. } \\
\text { - Materials and structures to decontaminate in place or remove, i.e., source reduction. } \\
\text { - What decontamination technologies to use (e.g., reagent and delivery system). } \\
\text { - Appropriate process parameters and analytical techniques. } \\
\text { - Waste disposal decisions. }\end{array}$ \\
\hline & $\square$ & Include Ambient Air Monitoring Plan (AAMP) in RAP, as required. \\
\hline & $\square$ & $\begin{array}{l}\text { Prepare Clearance Sampling and Analysis Plan (SAP), including: } \\
\text { - Clearance zones. } \\
\text { - Sampling approach(es) for each zone (e.g., judgmental and random or statistical sampling). } \\
\text { - Air sampling, as necessary. }\end{array}$ \\
\hline \multirow{2}{*}{$\begin{array}{l}\text { Operations Section: } \\
\text { Decontamination Group }\end{array}$} & $\square$ & Perform source reduction. \\
\hline & $\square$ & Review draft RAP and SAP. \\
\hline \multirow[t]{2}{*}{ Safety Officer } & $\square$ & $\begin{array}{l}\text { Develop a specific Emergency Response Plan to address potential uncontrolled releases (e.g., } \\
\text { from explosion, fire, or hurricane) if toxic gas/vapor phase decontaminants are used. }\end{array}$ \\
\hline & $\square$ & Review and update HASP. \\
\hline UC & $\square$ & Approve the RAP and SAP with input from the TWG. \\
\hline $\begin{array}{l}\text { Operations Section: } \\
\text { Decontamination and Sampling } \\
\text { Groups }\end{array}$ & $\square$ & Perform all site preparations as specified in the RAP. \\
\hline \multirow{3}{*}{$\begin{array}{l}\text { Operations Section: } \\
\text { Decontamination Group }\end{array}$} & $\square$ & Conduct decontamination and monitor process parameters. \\
\hline & $\square$ & Conduct limited surface sampling as initial check of decontamination effectiveness. \\
\hline & $\square$ & $\begin{array}{l}\text { Evaluate whether decontamination process criteria are met. } \\
\text { - For gas/vapor phase decontamination (e.g., concentration, temperature, time) } \\
\text { - For surface decontamination (e.g., initial pH, contact time) } \\
\text { Recommend additional decontamination activities, as necessary. }\end{array}$ \\
\hline
\end{tabular}




\section{Checklist continued.}

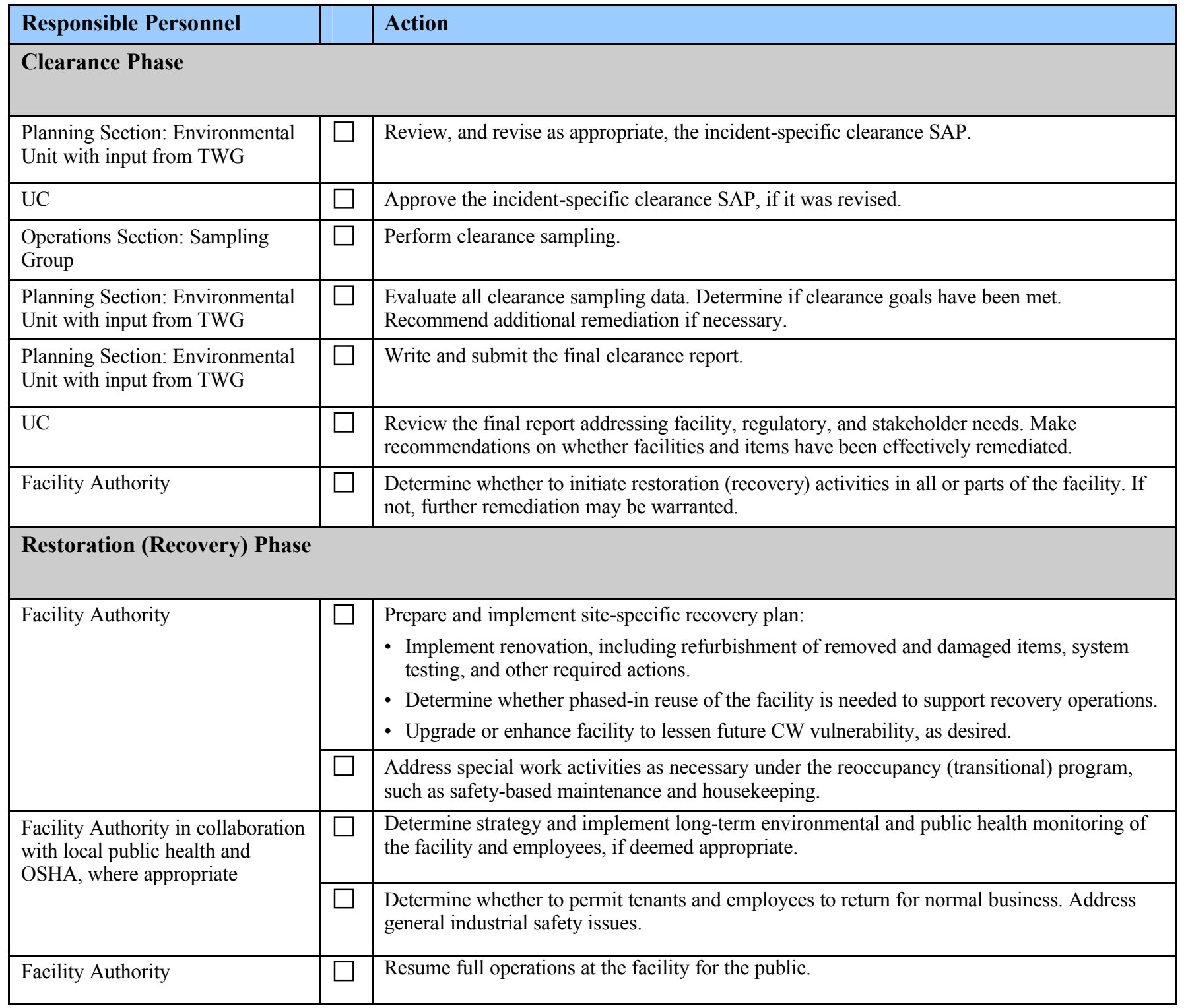




\section{Recommendations for Facility Preparedness}

The following list identifies preparedness activities a facility should conduct to expedite chemical restoration. Activities are listed under the response phase with which they are most closely associated.

\section{Initial Notification}

- Develop a notification protocol for all facility personnel, responders, and agencies (Federal, state, and local) tailored to each stage of a developing incident.

\section{First Response}

- Develop and incorporate specific chemical response plans into the facility's emergency response plan, as appropriate.

- Develop a policy specifying the criteria for facility closure or suspension of operations after a CWA attack. The policy should incorporate public health strategies and management of employees, rolling stock, and patrons.

- Develop risk communication plan.

- Conduct training exercises with likely command personnel, including responder and agency representatives.

\section{Remediation:}

- Identify members of a Unified Command (UC) and a Technical Working Group (TWG) (see Figure A-2).

- Ensure that UC and TWG members are familiar with facility-specific remediation plan(s) through exercises.

\section{Characterization}

- Identify characterization resources, such as sampling contractors and analytical laboratories.

- Identify potential isolation, containment, sampling, characterization, and gas/vapor phase decontamination zones within the facility.

- Identify sampling units (which may consist of surfaces, items, or sets of items) to be sampled.

- Identify areas at the facility that can be used or cleared for staging and storing waste materials.

- Create and maintain an up-to-date library of key facility architectural and mechanical drawings including heating, ventilation and air conditioning (HVAC) operating parameters.

- Create a new, or review and revise an existing, Health and Safety Plan (HASP).

\section{Decontamination}

- Identify in-house equipment that could be used or upgraded for remediation activities.

- Select staging areas or warehouses for equipment and supplies.

- Determine disposal and decontamination options for potentially contaminated materials and equipment.

- Determine likely facility decontamination method(s).

- Determine types of decontamination supplies to store.

- Select and retain contractors for the decontamination team.

- Identify staging and storage areas for waste.

- Establish agreements, if possible, with local waste-disposal facilities and wastewater treatment facilities.

- Identify waste-disposal options with solid waste management authority(ies).

\section{Clearance}

- Identify regulatory cleanup guidance.

- Ensure that most of the preplanning activities done under Characterization apply to Clearance.

\section{Restoration (Recovery)}

- Develop a Hazard Communication Plan, including written examples that would be used to inform employees and the general public about possible risks associated with reoccupancy.

- Identify long-term air monitoring options to meet stakeholder needs.

- Determine priorities for bringing facility back online.

- Conduct facility evaluations to identify CWA vulnerabilities, and address them, as appropriate.

- Identify potential facility upgrades to expedite remediation and minimize economic impact. 
Response, Remediation and Recovery Checklist

\section{Notes and References}

DHS (December 2004), Department of Homeland Security, National Response Plan, available at $<$ http://www.dhs.gov/dhspublic/interapp/editorial/editorial_0566.xml $>$.

Homeland Security Presidential Directive (HSPD-5), Management of Domestic Incidents, The White House, February 28, 2003.

LLNL (2007a), Lawrence Livermore National Laboratory, Remediation Guidance for Major Airports After a Chemical Agent Attack, Lawrence Livermore National Laboratory, Livermore, draft report; to be issued as a joint Department of Homeland Security and U.S. Environmental Protection Agency document.

LLNL (2007b), Lawrence Livermore National Laboratory, Remediation Guidance for Major Airports After a Bioterrorist Attack, Lawrence Livermore National Laboratory, Livermore, CA, UCRL-TR210178-DRAFT Rev. 2; to be issued as a joint Department of Homeland Security and U.S.

Environmental Protection Agency document.

NIMS (March 1, 2004), National Incident Management System, document available from FEMA at 1800-480-2520, Option 4, ask for FEMA 501.

Robert T. Stafford Disaster Relief and Emergency Assistance Act, 93 Pub. L. No. 288, 88 Stat 143 (1974) [codified as amended at 42 U.S.C. $\S \S 5121-5206$ and scattered sections of 12 U.S.C., 16 U.S.C., 20 U.S.C., 26 U.S.C., and 38 U.S.C. (2002)]. 


\section{Appendix A. Incident Command System}

The Incident Command System (ICS) is a standardized, flexible, on-scene, emergency management construct specifically designated to provide for the adoption of an integrated organizational structure that reflects the complexity and demands of single or multiple incidents, without being hindered by jurisdictional boundaries. It includes the combination of facilities, equipment, personnel, procedures, and communications operating within a common organizational structure and is designed to aid in managing resources during an emergency response, such as an incident involving a CWA or TIC. It is critical that the ICS structure remain flexible and adaptable. It can be resized and restructured as the incident unfolds, adding or disbanding various groups, as dictated by the incident. The consequence management organization structure shown in Figure A-1 shows typical relations among ICS organizations involved in consequence management of a chemical contamination incident.

Formation of a Technical Working Group (TWG) early in an incident is strongly recommended. This group of technical specialists helps to plan restoration operations and provides advice to the Incident Commander or Unified Commander, staff, and contractors.

Figure A-2 identifies some of the specialty areas that would be required of personnel who staff the Unified Command and TWG and the organizations that could provide representatives for each group. Technical roles played by members of the TWG are varied and challenging. For an incident involving a CWA or TIC, qualifications would include medical or restoration experience related to chemical contamination. 


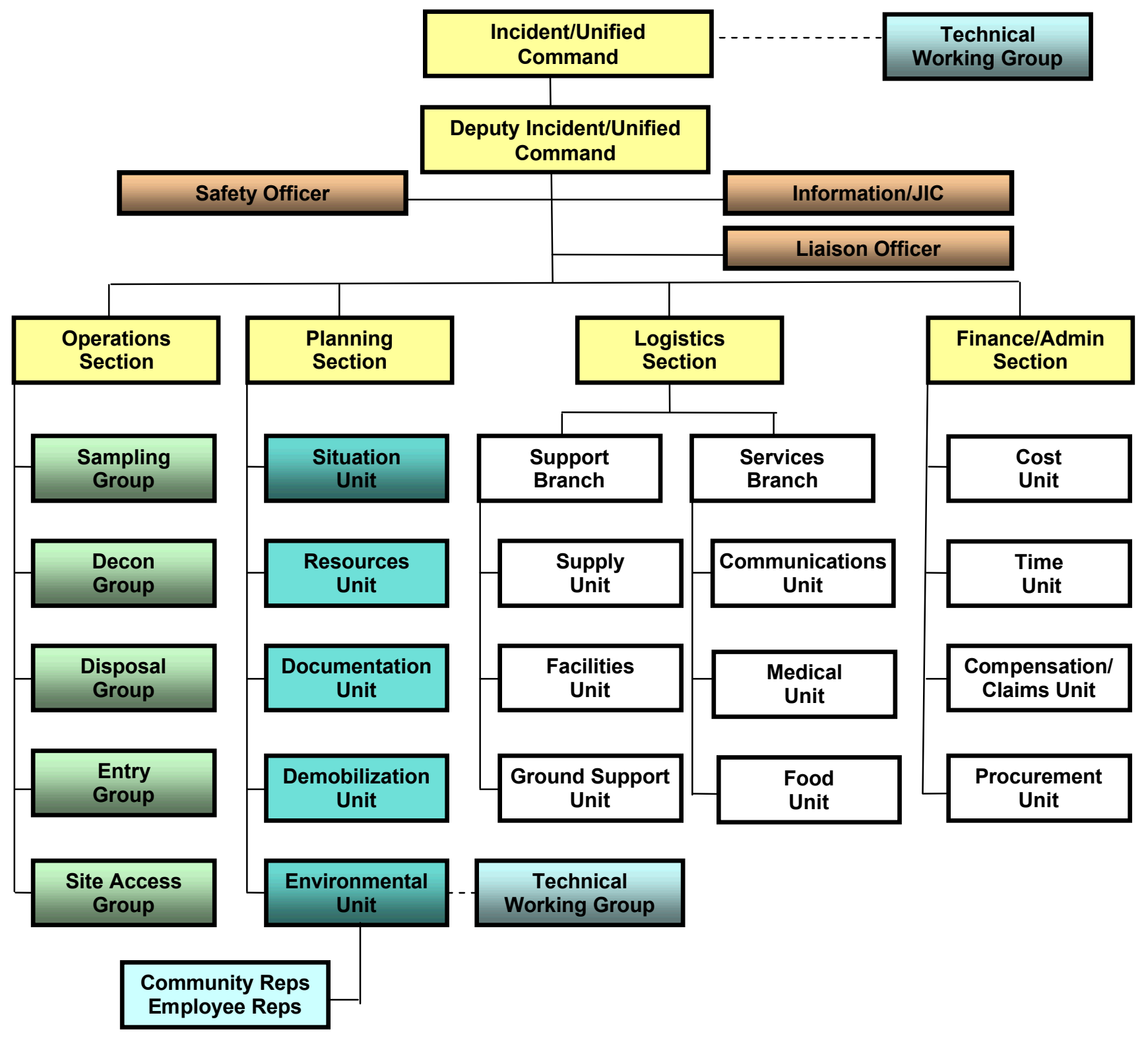

Figure A-1. ICS organizational structure with focus on the consequence management phase of a chemical incident remediation. See Figure A-2 for additional detail.

At the discretion of the UC, the TWG may either report directly to the UC or function under the direction of the Environmental Unit Leader. 


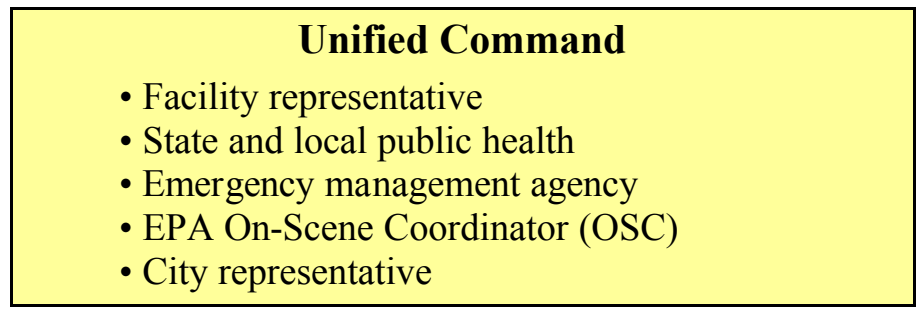

\begin{tabular}{|l|}
\hline \multicolumn{1}{|c|}{ Technical Working Group } \\
Areas of Required Expertise \\
- Organic and reactive chemistry \\
- Waste disposal (federal and state) \\
- Ambient air monitoring \\
- Environmental sampling \\
- Chemical analysis \\
- Chemical engineering \\
- Decontamination methods \\
Representatives from \\
- Facility \\
- CDC, NIOSH \\
- EPA \\
- State and local public health, analytical labs \\
- Other affected state and local agencies \\
- OSHA \\
- Private sector \\
- Universities
\end{tabular}

Figure A-2. Members and areas of required expertise of the Unified Command and Technical Working Group focused on the consequence management phase. 
Utwersity ofCalifornia

Lawrenoe Livermore National Laboratory

Technical Information Department

Livermone, CA 94551

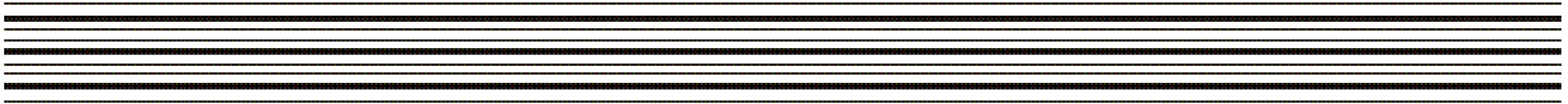

